\title{
Siegfried Matthus
}

\section{Die Tiefe der Musik}

\begin{abstract}
A ls Berliner Musikstudent besuchte ich im Jahre 1953 ein mehrAtägiges Bachfest mit Konzerten in der Thomaskirche in Leipzig. Was mir durch die Kriegsereignisse und die Flucht aus Ostpreußen bis dahin verwehrt geblieben war, konnte ich jetzt in einer Fülle von Aufführungen der Orgelwerke, der Kantaten und der Oratorien von Bach am historischen Ort seines Wirkens erleben. Es war ein umwerfendes Schlüsselerlebnis.

Kann man das Wort, den Begriff der "Tiefe« auf Musik anwenden? Ich habe keine andere Bezeichnung gefunden, die das ausdrückt, was ich bei der Musik von Johann Sebastian Bach empfinde. Tiefe, nicht als etwas Entferntes, sondern sehr Nahes, nicht als etwas Entschwindendes, sondern auf mich Zukommendes. Das tief Grüblerische, nicht als etwas Kompliziertes, sondern als ein höchst Einfaches.

So erlebe ich das harmonisch schlichte Gewand der Passionschoräle, die herzergreifende Traurigkeit in der melodischen Linie "und ging hinaus und weinete bitterlich", die gestische Dramatik in "Kreuzige", die bildhafte Zeichnung in »Und siehe da, der Vorhang im Tempel zerriß" und vieles andere. Die tief empfundene Menschlichkeit, die tiefe gläubige Gottesfürchtigkeit sind es, die mich bei Bachs Musik erschüttern und erheben.

Bachs Kompositionen gehören inzwischen zur Weltmusik. Sie zeugen aber in ihren tiefen Wurzeln von einer Besonderheit, die man weder in italienischen, in französischen, in englischen, in niederländischen noch in russischen Musikwerken findet - sie sind im schönsten und reinsten Sinne deutsche Musik.
\end{abstract}

